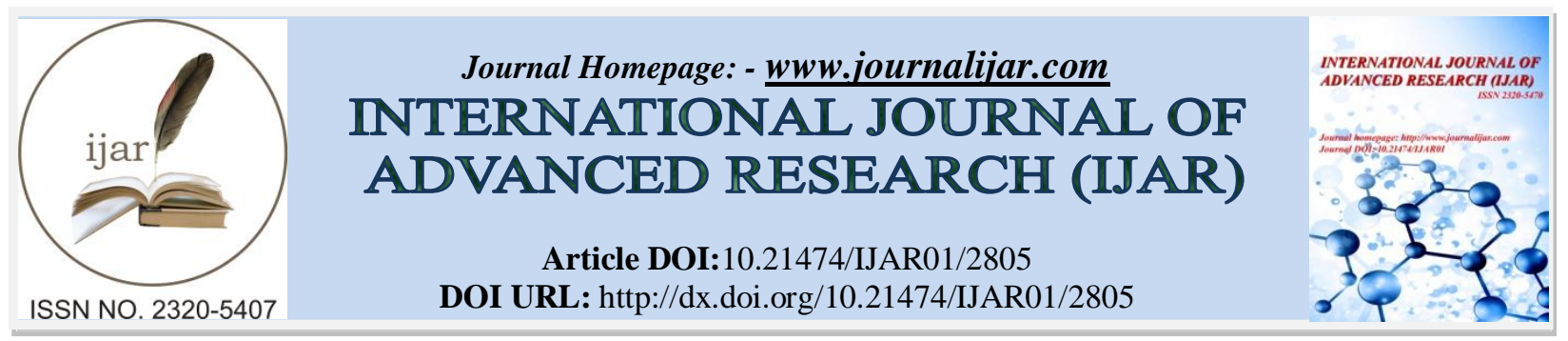

RESEARCH ARTICLE

\title{
CARDIOVASCULAR SYSTEM PROBLEMS AMONG GERIATRIC POPULATION OF ARAR CITY, KINGDOM OF SAUDI ARABIA: PREVALENCE AND DETERMINANTS
}

\section{Nagah Mohamed Abo El-Fetoh ${ }^{1}$, Fatimah FahadSaad Altaleb ${ }^{2}$, AseelMenwer Alanazi ${ }^{2}$, Hanan Khalid Alotaibi $^{2}$, Abdullah Ahmed Alsaileek ${ }^{3}$, AtheerMuteb Alanazi ${ }^{2}$, Omar Ayed Alanazi $^{2}$, MunifSaleh Alanazi ${ }^{2}$, Yasser Hamoud Alanazi ${ }^{2}$ and Ahmad Rami Aldeiri ${ }^{3}$.}

1. Associate Prof. of Public Health and Community Medicine, Faculty of Medicine, Northern Border University, KSA.

2. Student, Faculty of Medicine, Northern Border University, KSA.

3. Intern, Faculty of Medicine, Alfaisal University, Riyadh, KSA.

\section{Manuscript Info}

\section{Manuscript History}

Received: 15 November 2016

Final Accepted: 17 December 2016

Published: January 2017

Key words:-

elderly; cardiovascular diseases; hypertension; ischemic heart diseases; Arar; Northern Saudi Arabia.

\section{Abstract}

Abstract:

Background: Over the last twenty years, Saudi Arabia has witnessed major socioeconomic development leading to significant changes in its standard of living and lifestyle. This transformation of the society resulted in changes in dietary habits, compounded by a lack of exercise among elderly have contributed to the emergence of diseases, including hypertension and IHD and other important cardiovascular diseases.Objectives: To estimate the prevalence of cardiovascular system diseases, its types and its determinants among the elderly population of Arar city, Kingdom of Saudi Arabia. Participants and methods: A cross sectional study included 276 participant aged 60 years and above, attending 5 randomly selected primary healthcare centers in Arar city. Data was collected through personal interviews with the sampled elderly and filling the questionnaire which guided us to the data of socio-demographic characteristics, smoking status and diabetes millets. BMI was calculated. The questionnaire included questions regarding the cardiovascular system diseases, its types and its determinants, after ensuring the diagnosis and by reviewing the accompanied health reports and prescriptions and asking the caregivers about the case. Results: The overall prevalence of cardiovascular diseases was $73.2 \%$, hypertension was found in about half $(44.9 \%)$ of them, ischemic heart diseases in $18.9 \%$; Myocardial infarction was found in $10.9 \%$, Ischemia in $8.0 \%$ and Arrhythmias in $6.5 \%$ of the studied elderly population. There is insignificant relationship between the occurrence of hypertension and sex, age group, DM and obesity $(\mathrm{P}>0.05)$. But there is significant relation between the occurrence of hypertension and smoking in studied elderly population $(\mathrm{P}<0.05)$. There is significant relation between the occurrence of ischemic heart diseases and sex, age group, smoking and $\mathrm{DM}$ in studied elderly population $(\mathrm{P}<0.05)$. But there is insignificant relationship between the occurrence of ischemic heart

Corresponding Author:-Nagah Mohamed Abo El-Fetoh. 
diseases and obesity $(\mathrm{P}>0.05)$. Conclusion and recommendations: The study revealed that elderly were suffering from many cardiovascular diseases. Such common comorbidities as DM, obesity, and Smoking need decision makers to plan and implement more effective preventive, curative and rehabilitative services to improve the health status and the quality of life of those vulnerable group.

Copy Right, IJAR, 2016,. All rights reserved.

\section{Introduction:}

Aging is a natural biological process which is associated with deterioration of health status of elderly people. The ageing is inevitable and it is a concern of every one. Ageing is known as a process of deterioration in the functional capacity of a person that results from structural changes, with advancement of age [1].

The world will have more elderly people than children because economies are globalizing and the technologies are evolving rapidly [2].

Elderly life is full of problems- physical, social and economic. Older people are helpless and a disability is more likely to occur in the old age [3]. From 1990 through 2010, there was a decline in age-specific mortality in KSA. During the same time, life expectancy increased from 72.5 to 75.0 for men and from 76.3 to 79.9 for women. During the same time, healthy life expectancy increased from 61.8 to 63.9 for men and from 63.5 to 66.6 for women [4].

Over the last twenty years, Saudi Arabia has witnessed major socioeconomic development leading to significant changes in its standard of living and lifestyle. The transformation of the society has also resulted in changes in dietary habits and related social practices. This has been compounded by a lack of exercise among large segments of the society. These factors and others have contributed to the emergence of life style-related diseases, including hypertension and diabetes mellitus.[5].

Cardiovascular disease (CVD) is a class of diseases that involve the heart or blood vessels which are the leading cause of death globally.In the Cardiovascular Health Study which the prevalence of cardiovascular diseases in older Americans, the prevalence rates of definite myocardial infarction and angina were $11 \%$ and $15 \%$, respectively, among men aged 65-69 years, $18 \%$ and $17 \%$ among men aged $80-84$ years, $4 \%$ and $8 \%$ among women aged $65-69$ years, and $3 \%$ and $13 \%$ among women aged $80-84$ years [6].

In southwest Saudi Arabia, Al-Modeer study found that, the most prevalent cardiovascular disease is hypertension $(59.1 \%)$ followed by ischemic heart diseases $(16.7 \%)$ and arrhythmias occurred among $8.1 \%$ of study population; 8.9 in females $\%$ and $7.0 \%$ in males. Most of the cardiovascular morbidities have the same percent in both genders. Some diseases show significant $(\mathrm{P}<0.005)$ high prevalence among males such as hypertension, its prevalence among males was $63.7 \%$ compared to $55.5 \%$ in females [7].

In Fayum, Egypt, hypertension was the second prevalent disease (37.4) with more prevalence among males (19.3\%) than Females (18.2\%). CHD was 5.9\% 3.6\% in males and 2.2\% in females [8].

In a national study in KSA conducted by Al-Nozha et al., the overall prevalence of Coronary Artery Diseases obtained from this study is 5.5\% in KSA. The prevalence in males and females were $6.6 \%$ and $4.4 \%(\mathrm{P}<0.0001)$. Urban Saudis have a higher prevalence of $6.2 \%$ compared to rural Saudis of $4 \%$ ( $\mathrm{P}<0.0001)$. The following variables are found to be statistically significant risk factors in KSA: age, male gender, body mass index (BMI), hypertension, current smoking, fasting blood glucose, fasting cholesterol and triglycerides [9].

In a study conducted in Dubai, the most common prevalent disease was hypertension (67.5\%) [10]. In Udaipur, Rajasthan Vishnoi et al., found hypertension among elderly was 25\% it was 38.7 in females and 15.3 in males [11].

Assessment of the cardiovascular morbidity profile will help in the application of interventions, to keep and improve vision and the quality of life of the elderly. Yet, up to our knowledge, there is little or no baseline information on the prevalence of cardiovascular diseases in the elderly population in our region.

\section{Objectives:}

To estimate the prevalence of previously diagnosed cardiovascular system diseases, its types and its possible determinants among the elderly population of Arar city, Kingdom of Saudi Arabia.

\section{Participants and methods:}

Study design and setting :

The present cross sectional study was conducted in Arar city, which is the regional headquarter of the Northern Border Province of Saudi Arabia. 
Study period and target population: During the period from 1 June to 30 September 2016, on elderly people of age 60 years and more.

Sampling:

The sample size was calculated using the sample size equation: $n=z 2 p(1-p) / e 2$, considering target population more than 1000, and study power 95\%. Data was collected from 276 elderly participant aged 60 years and above, attending 5 randomly selected primary healthcare centers in Arar city. They were selected using a systemic random sampling procedure. Each participant was interviewed separately, and confidentiality was assured. Health centers provide healthy and sick citizens with healthcare services in an acceptable atmosphere of both privacy and confidentiality.

\section{Data collection:}

Data were collected by means of personal interview with the sampled elderly using a predesigned questionnaire covering the following items:

(1) Socio-demographic characteristics including age, sex, educational and marital status.

(2) Smoking status and certain types of diseases that may be prevalent among elderlies suggested to affect cardiovascular system diseases such as diabetes millets and thyroid gland diseases.

(3) Questions regarding the previously diagnosed cardiovascular system diseases, its types and its determinants, after ensuring the diagnosis and by reviewing the accompanied health reports and prescriptions and asking the caregivers about the case.

(4) Anthropometric examination included height and weight measurements with the use of a calibrated balance beam scale and a wall-mounted stadiometer and calculation of body mass index (BMI). Normal weight was defined as $\mathrm{BMI}<25 \mathrm{~kg} / \mathrm{m} 2$, overweight as $25 \leq \mathrm{BMI}<30 \mathrm{~kg} / \mathrm{m} 2$ and obesity as $\mathrm{BMI} \geq 30 \mathrm{~kg} / \mathrm{m} 2$ [16].

\section{Ethical considerations}

Data collector gave a brief introduction to the participants by explaining the aims and benefits of the study. Informed written consent was obtained from all participants. Anonymity and confidentiality of data were maintained throughout the study. There was no conflict of interest.

\section{Statistical analysis}

We utilized the statistical package for social sciences, version 16 (SPSS Inc., Chicago, Illinois, USA) to analyze the study data. The results were displayed as counts and percentages. The X2 test was used as a test of significance, and differences were considered significant at $\mathrm{P}$ value less than 0.05 .

\section{Results:}

Table (1) illustrates the socio-demographic characteristics and BMI status of the studied elderly population. The table showed that mean age $( \pm \mathrm{SD})$ was $70( \pm 9.25)$ years, male to female ratio was 47.8 to 52.2 , married were 88.4 while 9.4 were widow, illiteracy constitutes $52.9 \%$ and $20.3 \%$ completed primary education, $13 \%$ preparatory and $13.8 \%$ completed the secondary education. Regarding working status, most of the participants (38.4\%) haven't work while $33.3 \%$ were retired, $15.2 \%$ house wives and $10.9 \%$ were Shepherd. D.M was found in $37.0 \%$ and $44.9 \%$ were hypertensive. About half (45.7\%) were obese, $26.8 \%$ underweight and only $24.6 \%$ had normal weight.

Table (2) illustrates the percentage distribution of cardiovasculardiseases among the studied elderly population. The overall prevalence of cardiovasculardiseases was $73.2 \%$, hypertension was found in about half $(44.9 \%)$ of them, ischemic heart diseases in 18.9\%; Myocardial infarction was found in 10.9\%, Ischemia in $8.0 \%$ and Arrhythmias in $6.5 \%$ of the studied elderly population.

Table (3) illustrates the relationship between hypertension and socio-demographic characters, obesity and D.M in the studied elderly population. There is insignificant relationship between the occurrence of hypertension and sex, age group, DM and obesity $(\mathrm{P}>0.05)$. But there is significant relation between the occurrence of hypertension and smoking in studied elderly population $(\mathrm{P}<0.05)$.

Table (4) illustrates the relationship between ischemic heart diseases and socio-demographic characters, obesity and D.M in the studied elderly population. There is significant relation between the occurrence of ischemic heart diseases and sex, age group, smoking and DM in studied elderly population $(\mathrm{P}<0.05)$. But there is insignificant relationship between the occurrence of ischemic heart diseasesand obesity $(\mathrm{P}>0.05)$.

Table (1): Socio-demographic characteristics, chronic diseases and BMI status of the studied elderly population, Arar, 2016

\begin{tabular}{|c|r|rr|}
\hline Age group & No. $(\mathbf{n = 2 7 6})$ & \% & \\
\hline$\bullet \quad 60-$ & 180 & & 65.2 \\
\hline$\bullet \quad 70-$ & 72 & & 26.1 \\
\hline
\end{tabular}




\begin{tabular}{|c|c|c|}
\hline - $80+$ & 24 & 8.7 \\
\hline Mean age $( \pm$ SD $)$ & \multicolumn{2}{|c|}{$\frac{1}{70 \pm 9.25}$} \\
\hline \multicolumn{3}{|l|}{ Sex } \\
\hline - $\quad$ Female & 144 & 52.2 \\
\hline - $\quad$ Male & 132 & 47.8 \\
\hline \multicolumn{3}{|l|}{ Marital status } \\
\hline - $\quad$ Widow & 26 & 9.4 \\
\hline - $\quad$ Married & 244 & 88.4 \\
\hline - $\quad$ Divorced & 6 & 2.2 \\
\hline \multicolumn{3}{|l|}{ Educational level } \\
\hline - $\quad$ Illiterate & 146 & 52.9 \\
\hline - $\quad$ Primary & 56 & 20.3 \\
\hline - $\quad$ Preparatory & 36 & 13.0 \\
\hline - Secondary & 38 & 13.8 \\
\hline \multicolumn{3}{|l|}{ Working status } \\
\hline - Shepherd & 30 & 10.9 \\
\hline - House wife & 42 & 15.2 \\
\hline - $\quad$ Military & 6 & 2.2 \\
\hline - No work & 106 & 38.4 \\
\hline - $\quad$ Retired & 92 & 33.3 \\
\hline \multicolumn{3}{|l|}{ Chronic diseases } \\
\hline - $\quad$ DM & 102 & 37.0 \\
\hline \multicolumn{3}{|l|}{ BMI $\left(\mathrm{kg} / \mathrm{m}^{2}\right)$ status } \\
\hline - Underweight & 8 & 2.9 \\
\hline - $\quad$ Normal & 68 & 24.6 \\
\hline - Overweight & 74 & 26.8 \\
\hline - $\quad$ Obese & 126 & 45.7 \\
\hline Mean BMI ( \pm SD) & 29.99 & \\
\hline - Shepherd & 30 & 10.9 \\
\hline - House wife & 42 & 15.2 \\
\hline
\end{tabular}

Table (2): Percentage distribution of cardiovascular diseases in the studied geriatric population, Arar, 2016

\begin{tabular}{|l|c|c|}
\hline Cardiovascular diseases & No. $(\mathrm{n}=276)$ & $\%$ \\
\hline Yes & $\mathbf{2 0 0}$ & $\mathbf{7 2 . 5}$ \\
\hline Hypertension & 124 & 44.9 \\
\hline Ischemic heart diseases & 52 & 18.9 \\
\hline $\boldsymbol{\bullet}$ Myocardial infarction & 30 & 10.9 \\
\hline $\boldsymbol{\bullet}$ Angina pectoris & 22 & 8.0 \\
\hline Arrhythmias & 18 & 6.5 \\
\hline Coronary artery bypass operation & 2 & .7 \\
\hline Hypertension and previous myocardial infarction & 2 & .7 \\
\hline Valve diseases & 2 & .7 \\
\hline No & $\mathbf{7 6}$ & $\mathbf{2 7 . 5}$ \\
\hline
\end{tabular}

Table (3): the relationship between Hypertension and sex, age group, obesity and D.M in the studied elderly, Arar, 2016

Sex

\begin{tabular}{|c|c|c|c|c|}
\hline \multicolumn{2}{|c|}{ Hypertension } & \multirow{2}{*}{$\begin{array}{c}\text { Total } \\
(\mathbf{n}=276)\end{array}$} & $\begin{array}{c}\text { Chi- } \\
\text { square }\end{array}$ & $\begin{array}{c}\text { P } \\
\text { value }\end{array}$ \\
\hline No & Yes & &
\end{tabular}




\begin{tabular}{|c|c|c|c|c|c|}
\hline & $(n=150)$ & $(n=126)$ & & & \\
\hline - $\quad$ Female & $74(49.3)$ & $70(55.6)$ & $144(52.2)$ & \multirow[t]{2}{*}{0.531} & \multirow[t]{2}{*}{0.289} \\
\hline - Male & $76(50.7)$ & $56(44.4)$ & $172(47.8)$ & & \\
\hline \multicolumn{6}{|l|}{ Age group } \\
\hline - 60 - & $102(68.0)$ & $78(61.9)$ & $180(65.2)$ & \multirow[t]{3}{*}{0.755} & \multirow[t]{3}{*}{.561} \\
\hline - 70 - & $36(24.0)$ & $36(28.6)$ & $72(26.1)$ & & \\
\hline - $80+$ & $12(8.0)$ & $12(9.5)$ & $24(8.7)$ & & \\
\hline \multicolumn{6}{|l|}{ Smoking history } \\
\hline - Non smoker & $90(60.0)$ & $100(79.4)$ & $190(68.8)$ & \multirow[t]{3}{*}{5.98} & \multirow[t]{3}{*}{0.050} \\
\hline - $\quad$ Smoker & $14(9.3)$ & $6(4.8)$ & $20(7.2)$ & & \\
\hline - Ex-smoker & $46(30.7)$ & $20(15.9)$ & $66(23.9)$ & & \\
\hline \multicolumn{6}{|l|}{ Diabetes } \\
\hline - Diabetic & $54(36.0)$ & $48(38.1)$ & $102(37.0)$ & \multirow[t]{2}{*}{0.065} & \multirow[t]{2}{*}{0.469} \\
\hline - Non diabetic & $96(64.0)$ & $78(61.9)$ & $174(63.0)$ & & \\
\hline \multicolumn{6}{|l|}{ Obesity } \\
\hline - $\quad$ Non obese & $82(54.7)$ & $68(54.0)$ & $150(54.3)$ & \multirow[t]{2}{*}{0.007} & \multirow[t]{2}{*}{0.535} \\
\hline - $\quad$ obese & $68(45.3)$ & $58(46.0)$ & $126(45.7)$ & & \\
\hline
\end{tabular}

Table (4): the relationship between ischemic heart diseases and sex, age group, obesity and D.M in the studied elderly, Arar, 2016

\begin{tabular}{|c|c|c|c|c|c|}
\hline \multirow[t]{2}{*}{ Sex } & \multicolumn{2}{|c|}{ Ischemic heart diseases } & \multirow{2}{*}{$\begin{array}{c}\text { Total } \\
(\mathbf{n}=\mathbf{2 7 6})\end{array}$} & \multirow{2}{*}{ Chi-square } & \multirow[t]{2}{*}{$P$ value } \\
\hline & $\begin{array}{c}\text { No } \\
(n=224)\end{array}$ & $\begin{array}{c}\text { Yes } \\
(n=52)\end{array}$ & & & \\
\hline - $\quad$ Female & $128(57.1)$ & $16(30.8)$ & $144(52.2)$ & \multirow[t]{2}{*}{5.88} & \multirow[t]{2}{*}{0.01} \\
\hline - Male & $96(42.9)$ & $36(69.2)$ & $132(47.8)$ & & \\
\hline \multicolumn{6}{|l|}{ Age group } \\
\hline - 60 - & $156(69.6)$ & $24(46.2)$ & $180(65.2)$ & \multirow[t]{3}{*}{14.03} & \multirow[t]{3}{*}{0.001} \\
\hline - 70 - & $44(19.6)$ & $28(53.8)$ & $72(26.1)$ & & \\
\hline - $80+$ & $24(10.7)$ & $0(0)$ & $24(8.7)$ & & \\
\hline \multicolumn{6}{|l|}{ Smoking history } \\
\hline - Non smoker & $156(69.6)$ & $34(65.4)$ & $190(68.8)$ & \multirow[t]{3}{*}{5.98} & \multirow[t]{3}{*}{0.050} \\
\hline - Smoker & $10(4.5)$ & $10(19.2)$ & $20(7.2)$ & & \\
\hline - $\quad$ Ex-smoker & $58(25.9)$ & $8(15.4)$ & $66(23.9)$ & & \\
\hline \multicolumn{6}{|l|}{ Diabetes } \\
\hline - $\quad$ Diabetic & $72(32.1)$ & $30(57.7)$ & $102(37.0)$ & \multirow[t]{2}{*}{5.91} & \multirow[t]{2}{*}{0.015} \\
\hline - Non diabetic & 152(67.9) & $22(42.3)$ & $174(63.0)$ & & \\
\hline \multicolumn{6}{|l|}{ Obesity } \\
\hline - $\quad$ Non obese & $118(52.7)$ & $32(61.5)$ & $150(54.3)$ & \multirow[t]{2}{*}{0.668} & \multirow[t]{2}{*}{0.276} \\
\hline - $\quad$ Obese & $106(47.3)$ & $20(38.5)$ & $126(45.7)$ & & \\
\hline
\end{tabular}

\section{Discussion:}

Saudi Arabia like most countries in the world is facing the challenge of an ageing population. The recent increases in the proportion of elderly has raised attention to issues concerning the morbidity profile of this potentially vulnerable age group. The Physical functioning and psychological wellbeing of elderly are influenced by their morbidities. (12)

This study is a cross-sectional study was carried out in Arar city, the capital of the Northern Province of KSA, during the period from 1 June to 30 September 2016, on 138 elderly people of age 60 years and more.

In this study hypertension was the most common among these morbidities (44.9\%) and is also found to be more prevalent among females (55.6\%) than males (44.4\%), however the gender difference was insignificant $(\mathrm{P}>0.05)$. 
In Al-Modeer study hypertension was the most common among these morbidities (59.1\%) and is also found to be more prevalent among males than females this isn't in agreement with findings of our study [7]. In Dubai study, the most common prevalent disease among studied elderly was hypertension (67.5\%) [10] which is more than our figure. In Fayoum, Egypt, hypertension was the second prevalent disease (37.4) with more prevalence among males than females [8]. Other studies found hypertension was (73.6\% and $67.9 \%$ among males) [13,14]. In Udaipur, hypertension among elderly was $25 \%$, it was more prevalent in females than males (38.7 Vs. 15.3) [11] which is consistent with our result, but the figure is less than our figure.

The gender differences may result from biological differences, but they may be due to other comorbidity as obesity. A systematic review of the overall worldwide prevalence of hypertension, showed no gender difference [15] This study further supports this finding.

Results of the current study showed that Ischemic Heart Diseases was found in $18.9 \%$ of studied elderly population, it was more encountered among males compared to females $(\mathrm{P}<0.05)$. Results of the Fayoum, Egypt study showed that $5.9 \%$ of elderly had coronary heart disease (CHD) which was more encountered among males compared to females [8] this was greeted with our result but the figure is far less than us. Al-Modeer study found IHD in $16.7 \%$ of elderly (18\% in males and $15 \%$ in females) with insignificant difference between males and females $(\mathrm{P}>0.05)$ [8]. In Dubai study, Ischemic Heart Diseases was found in $15 \%$ of studied elderly population, with more prevalence among males than females (17.9\% Vs. 13.7\%) [10]. All are consistent with our findings. Results from the National Community Based Survey in the Saudi Arabia revealed that the prevalence of IHD was $9.3 \%$ and male gender was a risk factor [16].

In the current study arrhythmias occurred among $6.5 \% \%$ of study population, this finding is in accordance with AlModeer et al. findings, arrhythmias occurred among $8.1 \%$ of study population; 8.9 in females $\%$ and $7.0 \%$ in males $[8]$.

In the current study, there is significant relation between the occurrence of ischemic heart diseases and age group, smoking and $\mathrm{DM}$ in studied elderly population $(\mathrm{P}<0.05)$. But there is insignificant relationship between the occurrence of ischemic heart diseasesand obesity ( $\mathrm{P}>0.05)$. National Community Based Survey in the Saudi Arabia revealed that the prevalence of IHD among elderly aged 60-70 years was lower [16].

In a national study in KSA conducted by Al-Nozha et al., the following variables were found to be statistically significant risk factorsof ischemic heart diseases: age, male gender, obesity, hypertension, current smoking andDiabetes [9].

\section{Conclusion and recommendations:}

The study revealed that elderly were suffering from many cardiovascular diseases. Such common comorbidities as DM, obesity, and Smoking need decision makers to plan and implement more effective preventive, curative and rehabilitative services to improve the health status and the quality of life of those vulnerable group.

\section{Acknowledgements:}

The authors thankAbdalla Mohamed Bakr Ali ( Medical student, Sohag University, Egypt), Muaz Bilal Wali, Nasser G. Alshamari, Raed Khalid Raja Alanazi, Mahmoud Mohammed Alsharif (Medical Students, NBU), Hasan Mohammed Alarawi (Intern, Faculty of Medicine, Alfaisal University, Riyadh, KSA), ThamerOwaidAlanazi, AbdulrahmanMazkiAlanazi (Intern, Faculty of Medicine, NBU) and Duaa Mohammed Ali Alahdal (Intern, IbnSina National College for Medical Studies) for their help in different steps of the research.

\section{References:}

1-Harman D. The free radical theory of aging (2003). Antioxid Redox Signal, 5(5):557-561.

2. Banker K1, Prajapati B, Kedia G: Study Of Health Profile Of Residents Ofgeriatric Home In Ahmedabad.District National Journal of Community Medicine, 2 .(3) 2011 Page 378.

3. Balamurugan J, Ramathirtham G. Health problems of aged people, IJRSS, 2012 ; 2(3) : 139-150.

4- Memish ZA, Jaber S, Mokdad AH, AlMazroa MA, Murray CJ, Al Rabeeah AA, et al. Burden of Disease, Injuries, and Risk Factors in the Kingdom of Saudi Arabia, 1990-2010. Prev Chronic Dis 2014;11:140176.

5- Bani IA. Prevalence and related risk factors of Essential Hypertension in Jazan region, Saudi Arabia. Sudanese J Public Health. 2011;6:45-50 
6- Mittelmark MB, Psaty BM, Rautaharju PM, Fried LP, Borhani NO, Tracy RP, Gardin JM, O'Leary DH. Prevalence of Cardiovascular Diseases among Older Adults. The Cardiovascular Health Study. Am. J. Epidemiol. (1993) 137 (3): 311-317.

7- Al-Modeer M, Hassanien S, Jabloun C. Profile of morbidity among elderly at home health care service in Southern Saudi Arabia (2013). J Family Community Med, 20(1):53-57.

8- Hassan SK. A Study of Morbidity Pattern among Geriatric Population in Fayoum Governorate, Egypt. Journal of American Science 2015;11(4).

9- Al-Nozha MM, Arafah MR, Al-Mazrou YY, Al-Maatouq MA, Khan NB, Khalil MZ, et al. Coronary artery disease in Saudi Arabia. Saudi Med J. 2004;25:1165-71. [PubMed]

10- AnoodAlShaaliAmal Al Jaziri. Health profile of elderly patients registered in the Elderly Home Based Primary Care, Dubai, United Arab Emirates. Middle East Journal of Age and Ageing Volume 12 Issue 1, February 2015

11- Mohammed Ubaidula, Inamdar IF Aswar NR Doibale MK. Medical and psychosocial profile of geriatric population IOSR-JDMS 2014; 13(3): 29-33.

12- Joshi K, Kumar R, Avasthi A. Morbidity profile and its relationship with disability and psychological distress among elderly people in Northern India (2003). International Journal of Epidemiology, 32(6):978-987.

13- Bani IA. Prevalence and related risk factors of Essential Hypertension in Jazan region, Saudi Arabia. Sudanese J Public Health. 2011;6:45-50.

14- Al-Nozha MM, Abdullah M, Arafah MR, Khalil MZ, Khan NB, Al-Mazrou YY, et al. Hypertension in Saudi Arabia. Saudi Med J. 2007;28:77-84. [PubMed].

15- Kearney P, Whelton M, Reynolds K, Muntner P. Global burden of hypertension: analysis of worldwide data. Lancet. 2005;365:217-23. [PubMed]

16. Al-Nozha MM, Arafah MR, Al-Mazrou YY, Al-Maatouq MA, Khan NB, Khalil MZ, et al. Coronary artery disease in Saudi Arabia. Saudi Med J. 2004;25:1165-71. [PubMed] 